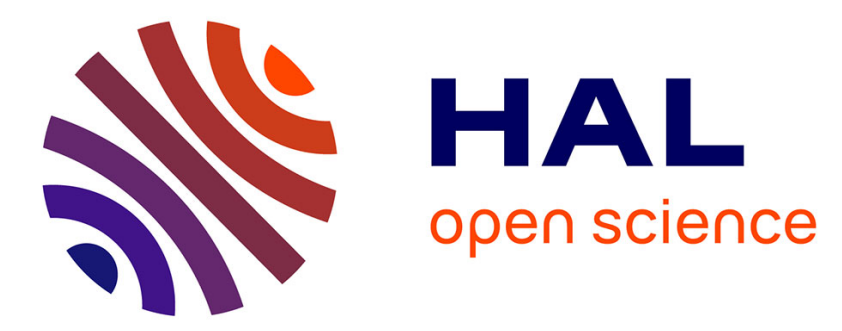

\title{
Regarding "Segmentation of heterogeneous or small FDG PET positive tissue based on a 3D-locally adaptive random walk algorithm" By DP. Onoma et al.
}

Mathieu Hatt, Dimitris Visvikis

\section{To cite this version:}

Mathieu Hatt, Dimitris Visvikis. Regarding "Segmentation of heterogeneous or small FDG PET positive tissue based on a 3D-locally adaptive random walk algorithm" By DP. Onoma et al.. Computerized Medical Imaging and Graphics, 2015, 46 (3), pp.300-1. inserm-01314334

\section{HAL Id: inserm-01314334 https://www.hal.inserm.fr/inserm-01314334}

Submitted on 11 May 2016

HAL is a multi-disciplinary open access archive for the deposit and dissemination of scientific research documents, whether they are published or not. The documents may come from teaching and research institutions in France or abroad, or from public or private research centers.
L'archive ouverte pluridisciplinaire $\mathbf{H A L}$, est destinée au dépôt et à la diffusion de documents scientifiques de niveau recherche, publiés ou non, émanant des établissements d'enseignement et de recherche français ou étrangers, des laboratoires publics ou privés. 
Regarding "Segmentation of heterogeneous or small FDG PET positive tissue based on a 3D-locally adaptive random walk algorithm" By DP. Onoma, et al.

Mathieu Hatt ${ }^{1}$ and Dimitris Visvikis ${ }^{1}$

${ }^{1}$ INSERM, UMR 1101, LaTIM, Brest, France.

Corresponding author: Mathieu Hatt

INSERM, UMR 1101, LaTIM

CHRU Morvan, 2 avenue Foch

29609, Brest, France

Tel: +33 2.98.01.81.11 - Fax: +33 2.98.01.81.24

e-mail: hatt@univ-brest.fr

Wordcount (total letter + response): 1690

Disclosure of Conflicts of Interest: No potential conflicts of interest.

Funding: None. 


\section{To the editor,}

We read with interest the paper of Onoma, et al. regarding the development and evaluation of a novel PET image segmentation method based on a random walk algorithm and called 3D-LARW [1]. In order to evaluate 3D-LARW, it was applied to three different datasets: a physical phantom containing homogeneous spheres acquired in a single PET/CT scanner, synthetic heterogeneous tumors generated by blurring and adding noise to a manually defined ground-truth, and 14 clinical tumors (for which the surrogate of truth was provided by manual delineations carried out by two different experts). This evaluation showed that 3D-LARW performed very well across the range of datasets considered.

After optimization, 3D-LARW was also compared with threshold-based methods (a fixed threshold at $40 \%$ of SUV $V_{\max }$ and an adaptive thresholding) and the FLAB approach [2].

Regarding the results reported for the homogeneous spheres in the phantom acquisition, FLAB obtained similar or worse results than both threshold-based methods. Similar hierarchy between FLAB and the threshold-based methods was reported for the synthetic heterogeneous tumours, both small and large, and the 14 clinical images.

The authors cited the original work presenting a 2-class implementation aimed at homogeneous uptakes delineation [2], but not the 3-class version of FLAB developed to delineate heterogeneous tumours [3]. As previously published, the 2-class version applied to heterogeneous objects is not appropriate and can only lead to unsatisfactory results [3]. On the one hand, this could contribute in explaining the poor results compared to threshold-based methods reported in this work for heterogeneous objects, in contradiction to previously published results using FLAB with three classes [3]-[6] (see also figure 1).
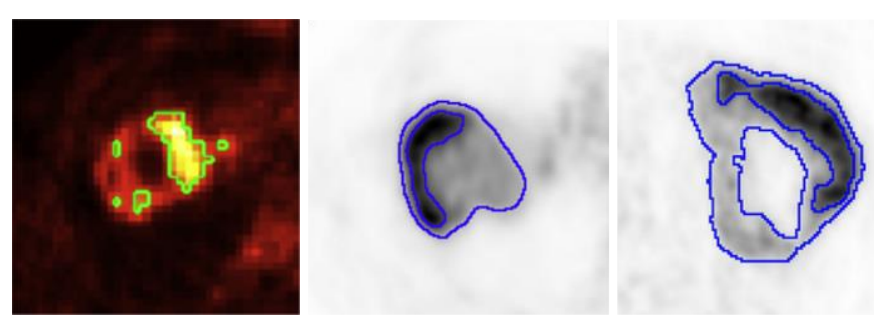

Figure 1. On the left, the result of FLAB applied to a heterogeneous tumour, reproduced from [1]. In the middle and on the right, results of FLAB using 3 classes, applied to two similarly heterogeneous tumours, reproduced from [7][4].

On the other hand, the results of FLAB on the homogeneous spheres of the phantom acquisition are more surprising because they concern homogeneous uptakes. They contradict previously published results that demonstrated significant improvements of FLAB over threshold-based methods [2], [8], improvements similar to those demonstrated here for 3D-LARW. These results are also in disagreement with these published by different groups using the originally published FLAB implementation provided within the context of research agreements. It is worth noting that these works have covered different activity distribution patterns, contrasts, and noise levels with FDG as well as other radiotracers [9]-[12].

We should emphasize that these observations do not decrease in any way the merits of the 3D-LARW method as it was demonstrated to provide significant improvements over threshold-based methods. 
The comparison with FLAB carried out here raises the issue of comparing methods and reimplementing algorithms. Some (threshold-based methods for instance) are very easy to implement and associated results are thus fairly easy to reproduce. On the contrary, more complex methods may involve a higher level of know-how, implementation details and other parameterization choices, which may result in a substantial impact on the implemented method's performances, as it seems to have been the case here. This highlights the need to provide a rigorous framework for such a comparison, with both standardized datasets and optimized methods' implementation. The current efforts led by the American Association of Physicists in Medicine Task Group $211^{1}$ "Classification, Advantages and Limitations of the Auto-Segmentation Approaches for PET" in developing such a benchmarking framework (called 'PETASset') are promising in that regard. PETASset will provide, within a user-friendly interface, test datasets (phantom, simulated and clinical images with associated ground-truth), evaluation metrics and tools to compare and rank methods [13].

\footnotetext{
${ }^{1}$ http://aapm.org/org/structure/default.asp?committee code=TG211
} 
[1] D. P. Onoma, S. Ruan, S. Thureau, L. Nkhali, R. Modzelewski, G. A. Monnehan, P. Vera, and I. Gardin, "Segmentation of heterogeneous or small FDG PET positive tissue based on a 3D-locally adaptive random walk algorithm," Comput. Med. Imaging Graph. Off. J. Comput. Med. Imaging Soc., vol. 38, no. 8, pp. 753-763, Dec. 2014.

[2] M. Hatt, C. Cheze le Rest, A. Turzo, C. Roux, and D. Visvikis, "A fuzzy locally adaptive Bayesian segmentation approach for volume determination in PET," IEEE Trans Med Imaging, vol. 28, no. 6, pp. 881-93, Jun. 2009.

[3] M. Hatt, C. Cheze le Rest, P. Descourt, A. Dekker, D. De Ruysscher, M. Oellers, P. Lambin, O. Pradier, and D. Visvikis, "Accurate automatic delineation of heterogeneous functional volumes in positron emission tomography for oncology applications," Int J Radiat Oncol Biol Phys, vol. 77, no. 1, pp. 301-8, May 2010.

[4] M. Hatt, C. Cheze-le Rest, A. van Baardwijk, P. Lambin, O. Pradier, and D. Visvikis, "Impact of tumor size and tracer uptake heterogeneity in (18)F-FDG PET and CT non-small cell lung cancer tumor delineation," J Nucl Med, vol. 52, no. 11, pp. 1690-7, Nov. 2011.

[5] A. Le Maitre, M. Hatt, O. Pradier, C. Cheze-le Rest, and D. Visvikis, "Impact of the accuracy of automatic tumour functional volume delineation on radiotherapy treatment planning," Phys Med Biol, vol. 57, no. 17, pp. 5381-97, Sep. 2012.

[6] M. Hatt, A. L. Maitre, D. Wallach, H. Fayad, and D. Visvikis, "Comparison of different methods of incorporating respiratory motion for lung cancer tumor volume delineation on PET images: a simulation study," Phys Med Biol, vol. 57, no. 22, pp. 7409-30, Nov. 2012.

[7] M. Hatt, N. Boussion, C. Cheze-Le Rest, D. Visvikis, and O. Pradier, "[Metabolically active volumes automatic delineation methodologies in PET imaging: review and perspectives]," Cancer Radiother, vol. 16, no. 1, pp. 70-81; quiz 82, 84, Feb. 2012.

[8] M. Hatt, C. Cheze Le Rest, N. Albarghach, O. Pradier, and D. Visvikis, "PET functional volume delineation: a robustness and repeatability study," Eur J Nucl Med Mol Imaging, vol. 38, no. 4, pp. 663-72, Apr. 2011.

[9] A. I. J. Arens, E. G. C. Troost, B. A. W. Hoeben, W. Grootjans, J. A. Lee, V. Grégoire, M. Hatt, D. Visvikis, J. Bussink, W. J. G. Oyen, J. H. A. M. Kaanders, and E. P. Visser, "Semiautomatic methods for segmentation of the proliferative tumour volume on sequential FLT PET/CT images in head and neck carcinomas and their relation to clinical outcome," Eur. J. Nucl. Med. Mol. Imaging, vol. 41, no. 5, pp. 915-924, May 2014.

[10] L. Heijmen, L. F. de Geus-Oei, J. H. de Wilt, D. Visvikis, M. Hatt, E. P. Visser, J. Bussink, C. J. Punt, W. J. Oyen, and $\mathrm{H}$. W. van Laarhoven, "Reproducibility of functional volume and activity concentration in 18F-FDG PET/CT of liver metastases in colorectal cancer," Eur J Nucl Med Mol Imaging, vol. 39, no. 12, pp. 1858-67, Dec. 2012.

[11] N. Withofs, C. Bernard, C. Van der Rest, P. Martinive, M. Hatt, S. Jodogne, D. Visvikis, J. A. Lee, P. A. Coucke, and R. Hustinx, "FDG PET/CT for rectal carcinoma radiotherapy treatment planning: comparison of functional volume delineation algorithms and clinical challenges," J. Appl. Clin. Med. Phys. Am. Coll. Med. Phys., vol. 15, no. 5, p. 4696, 2014.

[12] B. Henriques de Figueiredo, C. Zacharatou, S. Galland-Girodet, J. Benech, H. De ClermontGallerande, F. Lamare, M. Hatt, L. Digue, E. De Mones Del Pujol, and P. Fernandez, "Hypoxia imaging with [18F]-FMISO-PET for guided dose escalation with intensity-modulated radiotherapy in head-and-neck cancers," Strahlenther. Onkol. Organ Dtsch. Rontgengesellschaft Al, Sep. 2014.

[13] B. Berthon, E. Spezi, C. Schmidtlein, A. Apte, P. Galavis, H. Zaidi, E. De Bernardi, J. Lee, A. Kirov, and inc. Other contributors, "PET-ASset: Development of a software platform for evaluating automatic PET segmentation methods," presented at the European Society for Radiotherapy \& Oncology annual meeting, 2014. 